\title{
O caráter performativo da linguagem do Movimento Escola sem Partido
}

\author{
Letícia Berneira Cardozo* \\ UFSC \\ Recebido em: 10/05/2019 \\ Aceito em: 29/11/2019
}

\begin{abstract}
Resumo: Este artigo busca investigar o caráter performativo da linguagem do "Movimento Escola sem Partido". Como embasamento teórico utilizar-se-á autores como Austin (1962), Derrida (1977) e Butler (1997), que discorrem sobre o caráter performativo da linguagem e a violência exercida através dos atos de fala. Ancorada nos pressupostos da pesquisa qualitativa, analisam-se aqui os comentários online de três publicações da página oficial do "Escola sem Partido", disponibilizados na rede social Facebook. Os comentários apontam para a força ilocucionária da linguagem, capaz de nomear, transformar, subverter o papel do professor e incitar práticas violentas.
\end{abstract}

Palavras-chave: Atos de fala. Performatividade. “Movimento Escola sem Partido".

\begin{abstract}
This paper aims to investigate the performative character of the language from the "School without Political Party Movement". Authors like Austin (1962), Derrida (1977) and Butler (1997), who discuss the performative character of language and the violence exercised through speech acts, will be used as theoretical basis. Anchored in the assumptions of qualitative research, it will be analyzed online comments in three posts from the official webpage "School without Political Party" at the social network Facebook. The comments indicate the illocutionary force of language, capable of naming, transforming, subverting the role of the teacher and inciting violent practices.
\end{abstract}

Keywords: Speech acts. Performativity. "School without Political Party Movement".

Resumen: Este artículo busca investigar el carácter performativo del lenguaje del "Movimiento Escuela sin Partido". Como base teórica se utilizarán los autores Austin (1962), Derrida (1977) y Butler (1997). Ellos discurren sobre el carácter performativo del lenguaje y la violencia ejercida mediante los actos de habla. Anclada en las premisas de la investigación cualitativa, se analizan aquí los comentarios online de tres publicaciones de la página oficial de la "Escuela sin Partido", disponibles en la red social Facebook. Los comentarios apuntan a la fuerza ilocucionaria del lenguaje, capaz de nombrar, transformar, subvertir el papel del profesor e incitar prácticas violentas.

Palabras clave: Actos de habla. Performatividad. "Movimiento Escuela sin Partido".

\section{Introdução}


De acordo com Mey (2001, p. 6), "a comunicação na sociedade acontece principalmente por meio da linguagem". ${ }^{1}$ Essa linguagem nasce da necessidade de os indivíduos em nomear e transformar o mundo que os rodeia. Para o autor, a coletividade detem o poder da criação, do controle e do acesso aos meios linguísticos e comunicativos. É justamente por este viés que os estudos pragmáticos se desenvolvem. A Pragmática, segundo Mey (2001), explora a linguagem dentro de um contexto de uso, além de determinar como esses contextos afetam e efetivam o uso da linguagem humana.

Um dos pontos de partida da Pragmática se deu a partir do trabalho do filósofo inglês John Langshaw Austin. Em sua obra seminal How to do things with words (1962), Austin rompe com a ideia de linguagem puramente descritiva e passa a compreendê-la como um modo de agir sob o mundo. A linguagem, portanto, ganha um caráter performativo, onde dizer algo pode significar fazer algo.

Ainda relacionado com a linguagem, tem-se notado nos últimos anos, um crescente uso de redes sociais que, segundo Recuero e Soares (2013) oferecem novos contextos para os processos de comunicação e para os discursos, criando condições para que novas e antigas práticas sociais emerjam e se popularizem nas redes sociais. Em meio a este novo contexto de comunicação, observa-se uma crescente construção políticodiscursiva que marginaliza o agir docente e o desenvolvimento de políticas públicas educacionais nos campos de gênero, sexualidade e formação cidadã. De cunho conservador, a querela é alavancada pelo Movimento Escola sem Partido (doravante MESP), pais/responsáveis e estudantes insatisfeitos com profissionais que possam se utilizar do espaço escolar para elucidar conteúdos de ordem ideológica.

Tendo em vista os recentes acontecimentos no campo político-educacional, este trabalho tem por objetivo investigar o caráter performativo da linguagem do MESP. Buscar-se-á desenvolver as ideias de como os atos de fala em torno do agir docente são construídos pelos usuários das redes sociais, como tais práticas discursivas circulam, se ritualizam e se legitimam na sociedade. Para tal, utilizar-se-á como embasamento teórico autores como Austin (1962), Derrida (1977) e Butler (1997). Essas referências fornecerão apoio para compreender o caráter performativo da linguagem, a violência

\footnotetext{
1 Tradução livre. Citação original: "Communication in society happens chiefly by means of language". Revista Investigações, Recife, v. 32, n. 2, p. 165 - 180, Dezembro/2019
} 
exercida por meio dos atos de fala, bem como possíveis acarretamentos na atuação docente e no ensino.

Para fins de organização, apresentar-se-á algumas considerações sobre o MESP. Posteriormente, discorrer-se-á sobre a Teoria dos Atos de Fala de J.L. Austin (1962) e como tal teoria pode elucidar um acontecimento social, notadamente a desvalorização do professor em decorrência da linguagem violenta utilizada pelos simpatizantes do movimento. A seguir, o percurso metodológico será descrito, partindo para a problematização dos atos de fala dos simpatizantes do MESP nas redes sociais. Nas considerações finais, a pesquisa e as principais conclusões destacadas a partir do presente estudo serão retomadas.

\section{Escola Sem Partido: da origem do movimento ao projeto de lei}

O Escola sem Partido, inicialmente compreendido como um movimento, emerge em 2004, tendo como idealizador o então procurador do Estado de São Paulo, Miguel Nagib. Segundo informações do site do movimento ${ }^{2}$, em setembro de 2003, Nagib toma a atitude de escrever uma carta aberta ao professor de História de sua filha. O documento buscava contestar uma suposta comparação feita em sala de aula entre Ernesto "Che" Guevara e São Francisco de Assis, denunciando, assim, o que considerava o "facciosismo político-ideológico" da disciplina supracitada.

A carta foi entregue ao professor, à orientação, à direção da escola e aos responsáveis dos alunos. A ausência de uma atitude enérgica pela diretoria frente à denúncia, a falta de reação dos pais frente ao exposto, o ato de defesa realizado pelos estudantes pró-professor, bem como várias mensagens repudiando a carta aberta acabaram contribuindo para a criação do movimento.

Levantando uma analogia entre o ato solidário direcionado ao professor de História com a Síndrome de Estocolmo33, Nagib busca lutar contra os abusos que os

$2<$ http://www.escolasempartido.org/sindrome-de-estocolmo/> Acesso em 19 de nov. de 2018.

${ }^{3} \mathrm{~A}$ expressão "Síndrome de Estocolmo" foi cunhada pelo psiquiatra Nils Bejerot para denominar um estado psicológico em que vítimas podem desenvolver um estado de simpatia ou amizade pelos seus próprios agressores quando subordinadas a longos períodos de ameaças. 
estudantes estão submetidos, eliminando assim o "grau de contaminação políticoideológica” (ESCOLA SEM PARTIDO, 2018) presente nas práticas pedagógicas do ensino básico e superior e nos materiais didáticos de ensino. Para Nagib,

A pretexto de transmitir aos alunos uma 'visão crítica' da realidade, um exército organizado de militantes travestidos de professores prevalece-se da liberdade de cátedra e da cortina de segredo das salas de aula para impingir-lhes a sua própria visão de mundo (ESCOLA SEM PARTIDO, 2018).

Por trás dessa visão crítica de ensino defendida pelos educadores e sustentados pela liberdade de cátedra, os professores estariam se beneficiando, cativando e formando novos seguidores de suas próprias ideologias. Nesse sentido, a criação do MESP busca denunciar esses professores, denominados doutrinadores, que pregam sua única visão de mundo e que perseguem os aprendizes que possam discordar da posição políticoideológica.

O MESP passa a ganhar notoriedade somente em 2014, quando o deputado estadual do Rio de Janeiro, Flávio Bolsonaro, se une a Nagib e ambos apresentam à Assembleia Legislativa do referido estado o projeto de lei (RIO DE JANEIRO, PL2974/2014) ${ }^{4}$. Neste projeto de lei, os autores se mostram contrários às práticas de doutrinação política e ideológica em sala de aula, repudiando conteúdos conflitantes com as convicções religiosas ou morais dos estudantes ou de seus responsáveis.

Hoje, o Projeto de lei 2974/2014 ganha capilaridade pelas Câmaras Municipais e Assembleias Legislativas de vários outros estados. Ademais, o MESP conta com o seu próprio sítio eletrônico - https://www.programaescolasempartido.org/_-para propagar suas próprias ideologias. O MESP também está presente nas redes sociais Facebook, possuindo cerca de 216 mil curtidas, no Instagram com cerca de 14,1 mil seguidores e no Twitter com aproximadamente 49 mil seguidores 5.

Além disso, os projetos visam controlar o trabalho docente por meio de denúncias e da divulgação de cartazes que especificam e lembram aos profissionais e estudantes os deveres dos professores, conforme anexo 1. Essas proposições são reforçadas pelo Art. $4^{\circ}$

\footnotetext{
4 Disponível em: <http://alerjln1.alerj.rj.gov.br/scpro1115.nsf/e4bb858a5b3d42e383256cee006ab66a/45741a7e2ccdc5 0a83257c980062a2c2? OpenDocument> Acesso em 20 de dez. de 2018.

5 Os números do MESP nas redes sociais foram atualizados em Dezembro de 2018.
}

Revista Investigações, Recife, v. 32, n. 2, p. 165 - 180, Dezembro/2019 
do projeto de lei supracitado, onde "Os conteúdos morais dos programas das disciplinas obrigatórias deverão ser reduzidos ao mínimo indispensável para que a escola possa cumprir sua função essencial de transmitir conhecimento aos estudantes" (RIO DE JANEIRO, PL2974/2014).

Cabe salientar que as proposições expressas pelo MESP e pelo projeto desrespeitam e violam direitos conquistados pela educação, ferindo princípios já estabelecidos pela Lei de Diretrizes e Bases da Educação Nacional (BRASIL, 1996) que, conforme o Artigo $3^{\circ}$, garante ao ensino os seguintes princípios:

I - Igualdade de condições para o acesso e permanência na escola;

II - Liberdade de aprender, ensinar, pesquisar e divulgar a cultura, o pensamento, a arte e o saber;

III - Pluralismo de ideias e de concepções pedagógicas;

IV - Respeito à liberdade e apreço à tolerância;

$\mathrm{V}$ - Coexistência de instituições públicas e privadas de ensino;

VI - Gratuidade do ensino público em estabelecimentos oficiais;

VII - Valorização do profissional da educação escolar;

VIII - Gestão democrática do ensino público, na forma desta Lei e da legislação dos sistemas de ensino;

IX - Garantia de padrão de qualidade;

X - Valorização da experiência extraescolar;

XI - Vinculação entre a educação escolar, o trabalho e as práticas sociais.

XII - Consideração com a diversidade étnico-racial.

XIII - Garantia do direito à educação e à aprendizagem ao longo da vida (BRASIL, Lei 9.394/1996, p. 1) ${ }^{6}$

Por fim, ressalta-se que tais medidas ferem a autonomia das escolas e dos professores, dificultando ou quase eliminando o papel da escola de construir um espaço educacional plural. A fragilidade do projeto acaba propiciando o apagamento de vozes e contribuindo para a manutenção do status quo, uma vez que o aprendiz não terá acesso a pensamentos críticos sobre os conhecimentos historicamente acumulados.

\section{A Teoria dos Atos de Fala e a performatividade da linguagem}

${ }^{6}$ Disponível em: <http://www.planalto.gov.br/ccivil 03/LEIS/L9394.htm>. Acesso em: 20 de dez. de $\underline{2018 .}$. 
A Teoria dos Atos de Fala é uma ideia seminal, originada de doze conferências proferidas pelo filósofo inglês John Langshaw Austin na Universidade de Harvard, EUA, em 1955. Sob o título inicial de Words and Deeds e publicadas postumamente como How to do things with words em 1962, Austin concebe a linguagem como uma forma de ação em que as condições de uso da linguagem podem atuar sobre o interlocutor e sob o mundo à volta.

Segundo Rajagopalan (2010), conceber a linguagem como forma de ação marca uma ruptura importante com o pensamento filosófico inspirado pela lógica positivista, ou seja, no conceito de que "uma sentença servia unicamente para descrever alguns estados de coisas ou para exprimir algum fato que pudesse ser verdadeiro ou falso"7 (AUSTIN, 1962, p.1). J.L. Austin tinha como objetivo investigar a linguagem do dia-a-dia, situada em um contexto e levando em consideração as intenções dos falantes, as escolhas linguísticas e as circunstâncias de fala, sem focar unicamente na estrutura formal da linguagem. Para tanto, Austin (1962) busca comprovar que algumas sentenças também possuem o caráter de exprimir uma ação conforme são proferidas. Essas sentenças cujo ato de enunciação permitem a realização de uma ação são classificadas por Austin como sentenças performativas, ao passo que as sentenças que apenas descrevem eventos são compreendidas como constativas. Para embasar sua concepção de sentenças performativas, Austin utiliza os exemplos abaixo:

(1) Eu aceito esta mulher como minha legítima esposa. $\rightarrow$ sentença proferida durante uma cerimômina de casamento;

(2) Eu batizo este navio como Rainha Elizabeth. $\rightarrow$ sentença proferida quando alguém quebra uma garrafa contra o casco do barco, e

(3) Eu dou e lego ao meu irmão o meu relógio. $\rightarrow$ sentença proferida quando ocorre um testamento.

7 Tradução livre. Trecho original: "a 'statement' can only be to describe some states of affairs, or to state some fact which must be either truly or falsely".

Revista Investigações, Recife, v. 32, n. 2, p. 165 - 188, Dezembro/2019 
Austin insiste que as supracitadas sentenças vão para além de uma pura descrição ou uma mera condição de verdade ou falsidade. As sentenças performativas, portanto, trazem à tona a premissa de que dizer algo pode ser compreendido como fazer algo. Segundo Austin (1962), as sentenças performativas estão sujeitas à condições de felicidade ou infelicidade a partir do momento em que o locutor satisfaz alguns princípios, a saber: a) cumprir com a existência de um procedimento convencionalmente aceito em que as pessoas, as palavras e as circunstâncias sejam adequadas ao procedimento; b) o procedimento deve ser executado por todos os participantes correto e completamente e c) o procedimento é projetado para o uso por pessoas com certos pensamentos, sentimentos e coerência. Portanto, se um enunciado performativo for pronunciado em circunstâncias inadequadas, ele pode ser infeliz ou nulo. O enunciado não terá efeito e, consequentemente, fracassará.

Entretanto, Austin anuncia em sua oitava conferência que, mesmo nas sentenças performativas, o ato de enunciar pode assumir características de declaração. No exemplo fornecido pelo filósofo "Saia - Ele me disse para sair!" ${ }^{8}$, a ação pode estar sendo performada por um sujeito ou a ação pode ser compreendida apenas como uma constatação ou declaração. Nas palavras de Austin:

Ao embarcar em um programa para encontrar uma lista de verbos performativos explícitos, parecia que não achávamos sempre fácil distinguir enunciados performativos de constativos, e, portanto, parecia conveniente voltar um pouco mais para os fundamentos - considerar desde o início até quantos sentidos há para se dizer algo é fazer alguma coisa, ou que dizer algo estamos fazendo alguma coisa, e até mesmo em que por dizer algo, fazemos alguma coisa (AUSTIN, 1962, p. 94). ${ }^{9}$

Nessa linha de pensamento, Austin desenvolve uma distinção entre os atos de fala como locucionário, ilocucionário e perlocucionário. Para o autor, o ato locucionário está relacionado com o ato de proferir um enunciado dotado de sentido e referência. $\mathrm{O}$ ato ilocucionário indica a razão para que um enunciado seja proferido, ou seja, a força

\footnotetext{
8Tradução livre. Sentença original: "Get out" - He told me to get out".

9Tradução livre. Trecho original: "In embarking on a programme of finding a list of explicit performative verbs, it seemed that we were going to find it not always easy to distinguish performative utterances from constative, and it therefore seemed expedient to go farther back for a while to fundamentals - to consider from the ground up how many senses there are in which to say something is to do something, or in saying something we do something, and even by saying something we do something".
} 
do ato em informar, ordenar, prevenir, avisar e comprometer-se em relação ao enunciado. Já o ato perlocucionário é relativo aos efeitos que um enunciado pode produzir no interlocutor, isto é, uma sentença pode carregar a intenção de convencer, persuadir, desencorajar, surpreender ou até confundir.

Portanto, para Austin, o que fazemos com a linguagem nos possibilita ir além de descrições. Um ato de fala pode possuir um caráter performativo, uma vez que quando proferimos algum enunciado também estamos querendo fazer algo com o que foi dito.

\subsection{Os atos de fala por uma visão desconstrucionista}

Na obra Assinatura Acontecimento Contexto (1977), Jacques Derrida realiza uma releitura de Austin. Segundo Derrida, o performativo "não se limita essencialmente a transportar um conteúdo semântico já constituído e vigiado por um aspecto da verdade” (DERRIDA, 1977, p.27). Para o filósofo francês,

[...] o performativo não tem seu referente (mas aqui essa palavra sem dúvida não convém o interesse da descoberta) fora de si ou, em todo caso, antes e perante si. Não descreve algo que existe fora da linguagem e antes dela. Produz ou transforma uma situação, opera [...] (DERRIDA, 1977, p. 26-27).

Nesta releitura, Derrida incide sob a intencionalidade dos sujeitos, compreendendo que a intenção não pode ser assumida de forma unilateral. É justamente a "presença consciente dos locutores ou receptores participando da efetuação de um performativo" (DERRIDA, 1977, p. 28) que permitirá o efeito, por exemplo, de haver uma celebração de um matrimônio, de um barco ser nomeado como Rainha Elizabeth e de um testamento ser cumprido.

Para Derrida, Austin parece desconsiderar uma eventual convencionalidade intrínseca da locução ao atentar-se apenas à "convencionalidade que forma a circunstância do enunciado, seu contorno contextual” (DERRIDA, 1977, p. 29). Assim, “o 'rito' não é uma eventualidade; é, como iterabilidade, um traço estrutural de toda marca” (DERRIDA, 1977, p. 29).

Além disso, Derrida compreende que os contextos e convencionalidades acionados pelos atos de fala podem projetar marcas de iterabilidade, isto é, a Revista Investigações, Recife, v. 32, n. 2, p. 165 - 180, Dezembro/2019 
possibilidade de um signo ser repetido e modificado. Paralelamente ao processo de repetição de um signo está a citacionalidade. Nas palavras de Derrida:

Qualquer signo, linguístico ou não-linguístico, falado ou escrito (no sentido corrente desta oposição), em pequena ou grande unidade, pode ser citado, posto entre aspas; por isso ele pode romper com todo contexto dado, engendrar ao infinito novos contextos, de modo absolutamente não saturável (DERRIDA, 1977, p. 25-26).

É nesse contexto que Judith Butler (1997) discute o uso da linguagem em ação, explorando as consequências políticas envolvidas quando enunciados são proferidos com a intenção de ofender, de injuriar e de fomentar violências. Para Butler (1997), os atos de fala também apresentam um caráter performativo, envolvidos de uma convencionalidade, sujeitos à citacionalidade e, consequentemente, carregados de consequências e responsabilidades.

Em Excitable speech: a politics of the performative (1997), Butler desenvolve essa noção de que enunciados podem estar travestidos de violências e, ao repetir determinadas falas, o sujeito também pode ser responsabilizado por eventuais consequências, muito embora a origem não tenha se dado no indivíduo em si. Para a pesquisadora,

[...] a citacionalidade do discurso pode funcionar para melhorar e intensificar nosso senso de responsabilidade por isso. Aquele que pronuncia a fala de ódio é responsável pela maneira como essa fala é repetida, por revigorar tal discurso, por restabelecer contextos de ódio e injúria. A responsabilidade do falante não consiste em ressaltar a linguagem ex nihilo, mas em negociar os legados de uso que limitam e permitem o discurso do falante (BUTLER, 1997, p. 27) ${ }^{10}$.

Para Butler, o sujeito que profere atos de fala carregados de injúrias acaba por renovar, reeditar e dar novo vigor ao discurso. Entende-se que "a responsabilidade está assim ligada à fala como repetição, não como originação"11 (BUTLER, 1997, p. 39). Mesmo dentro dessa iterabilidade em que os atos de fala podem reproduzir violências, a autora

\footnotetext{
10 Tradução livre. Citação original: "[...] the citationality of discourse can work to enhance and intensify our sense of responsibility for it. The one who utters hate speech is responsible for the manner in which such speech is repeated, for reinvigorating such speech, for reestablishing contexts of hate and injury. The responsibility of the speaker does not consist of remarking language ex nihilo, but rather of negotiating the legacies of usage that constrain and enable that speaker's speech".

11 Tradução livre. Citação original: "Responsibility is thus linked with speech as repetition, not as origination".
} 
reconhece a permanente dificuldade em localizar a responsabilidade final do falante e do seu próprio ato.

É nessa perspectiva sobre os atos de fala performativos instituídos em Austin (1962), Derrida (1977) e Butler (1997) que se dará a análise das iterações, citacionalidades, responsabilidades e consequências dos enunciados performados pelos simpatizantes do MESP.

\section{Percurso metodológico}

Partindo das considerações de Derrida (1977) de que os atos de fala podem ser vistos como performances situadas em contextos específicos, carregados de intenção e que podem ganhar forças perlocucionárias, este artigo busca analisar como os atos de fala em torno do agir docente são construídos, bem como suas possíveis consequências na sociedade.

Esta pesquisa se caracteriza como qualitativa interpretativa, pois, segundo Nunan (1992), as problematizações levantadas através da geração e análise de dados são oriundas de contextos e especificidades muito particulares, estando diretamente relacionado à maneira como o pesquisador estabelece a relação entre os dados e a linguagem.

A análise pragmática dos atos de fala dos simpatizantes do MESP dar-se-á por meio da observação de comentários online - feitos por usuários - em três publicações existentes na página oficial "Escola sem Partido" e disponibilizados na rede social Facebook. Justifica-se que o lócus de pesquisa atende ao grau de popularidade que a página alcança entre os adeptos do movimento e por acreditar, assim como Boyd (2010), que as redes sociais constituem um novo contexto de interação e, consequentemente, um novo tipo de público.

Os dados selecionados para análise obedecem a três momentos distintos, conforme tabela abaixo. É possível ainda visualizar a quantidade de curtidas, comentários e compartilhamentos que cada uma das publicações alcançou até a data de 12 de dezembro de 2018. 
Tabela 1: Sistematização dos dados coletados nas postagens

\begin{tabular}{|c|c|c|c|c|c|}
\hline Postagens & Assunto & Data & Curtidas & $\begin{array}{c}\text { Comentá- } \\
\text { rios }\end{array}$ & $\begin{array}{c}\text { Compartilha- } \\
\text { mentos }\end{array}$ \\
\hline Postagem 1 & Mordaça? & o8/o1/18 & 1,7 mil & 27 & 1.174 \\
\hline Postagem 2 & Denuncie! & $31 / 10 / 18$ & 4,4 mil & 182 & 8.524 \\
\hline Postagem 3 & $\begin{array}{c}\text { Arquiva- } \\
\text { mento do } \\
\text { Projeto de } \\
\text { Lei } \\
7180 / 2014\end{array}$ & $12 / 12 / 18$ & 976 & 120 & 468 \\
\hline
\end{tabular}

Fonte: Página Oficial do Movimento Escola sem Partido - Facebook

A coleta de dados se deu por meio de registro de congelamento de imagem (prints) dos comentários atribuídos aos posts selecionados. Justifica-se que pela grande quantidade de comentários nas publicações, optar-se-á por observar os enunciados onde haja uma maior discussão e posicionamento dos seguidores do MESP frente à temática. Mesmo reconhecendo a importância e o alto poder de iterabilidade das hashtags ${ }^{12}$ e emojis $^{13}$ nesses contextos digitais, os mesmos não serão foco de análise. Feitas as considerações metodológicas, passa-se então, à problematização dos dados.

\section{Análise dos dados - a performatividade dos discursos do MESP}

A partir das premissas teóricas levantadas sobre os atos de fala, buscar-se-á explorar os aspectos pragmáticos e a força ilocucionária presentes nos comentários

\footnotetext{
12 Recurso de agrupamento que identifica grupos ou conteúdos específicos em alguns sites, através do símbolo "\#", antes de uma palavra ou expressão, com o objetivo de facilitar a pesquisa pelo assunto com o qual esse símbolo se relaciona. Fonte: <https://www.dicio.com.br/hashtag/ >. Acesso em: 05 de dez. de 2019.

${ }^{13}$ Imagem que representa emoções, sentimentos, muito usada em aplicativos ou em conversas informais na Internet, embora tenha um significado particular, cada uma é interpretada de acordo com o contexto em que está inserida. Fonte: <https://www.dicio.com.br/emoji/>. Acesso em: 05 de dez. de 2019.
} 
online, capazes de atualizar e reestabelecer novos contextos e significados. Conforme o ponto de vista derridiano, os comentários selecionados visivelmente atuam dentro de um sistema de citacionalidade e iterabilidade, uma vez que há um espelhamento das falas produzidas por Nagib, constantemente reforçadas no sítio eletrônico do MESP e compartilhadas entre usuários seguidores da página.

Na primeira postagem selecionada (figura 1), a discussão gira em torno do termo "mordaça" utilizado pelos indivíduos que objetam o movimento. De acordo com a publicação, o professor que intitula o projeto como “mordaça” está publicamente confessando que é um doutrinador, uma vez que ele se sente impedido de disseminar suas próprias concepções políticas, ideológicas, morais ou religiosas.

Figura 1: Publicação 1 - "Mordaça?”

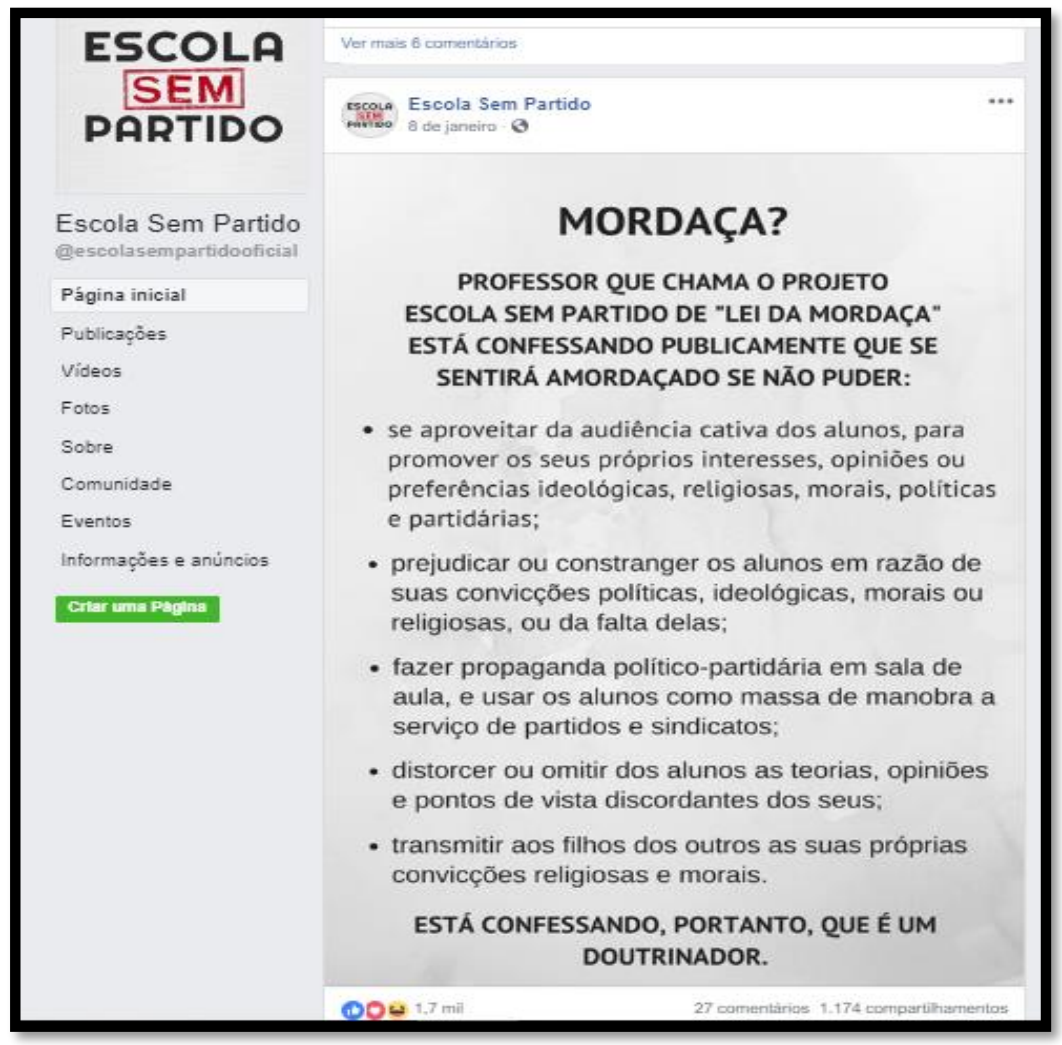

Fonte: Escola sem Partido Oficial - Facebook

Na publicação, ao se utilizarem de termos imprecisos como "doutrinação" e “ideologia”, o papel social, ético e político da escola é deturpado. Há a desqualificação 
do trabalho docente por meio da criação de uma ameaça abstrata que coloca em xeque todo o sistema educacional. A publicação é um ato de fala que possui uma força ilocucionária de um veredito, traçando uma linha divisória entre os professores que são contra ou a favor do movimento. Tem-se o sentido de divisão entre o bem e o mal, onde o cidadão precisa tomar uma posição de combate. Nos comentários abaixo, ter-se-á a noção dessa iterabilidade discursiva:

Figura 2: Comentários referentes à publicação "Mordaça?"

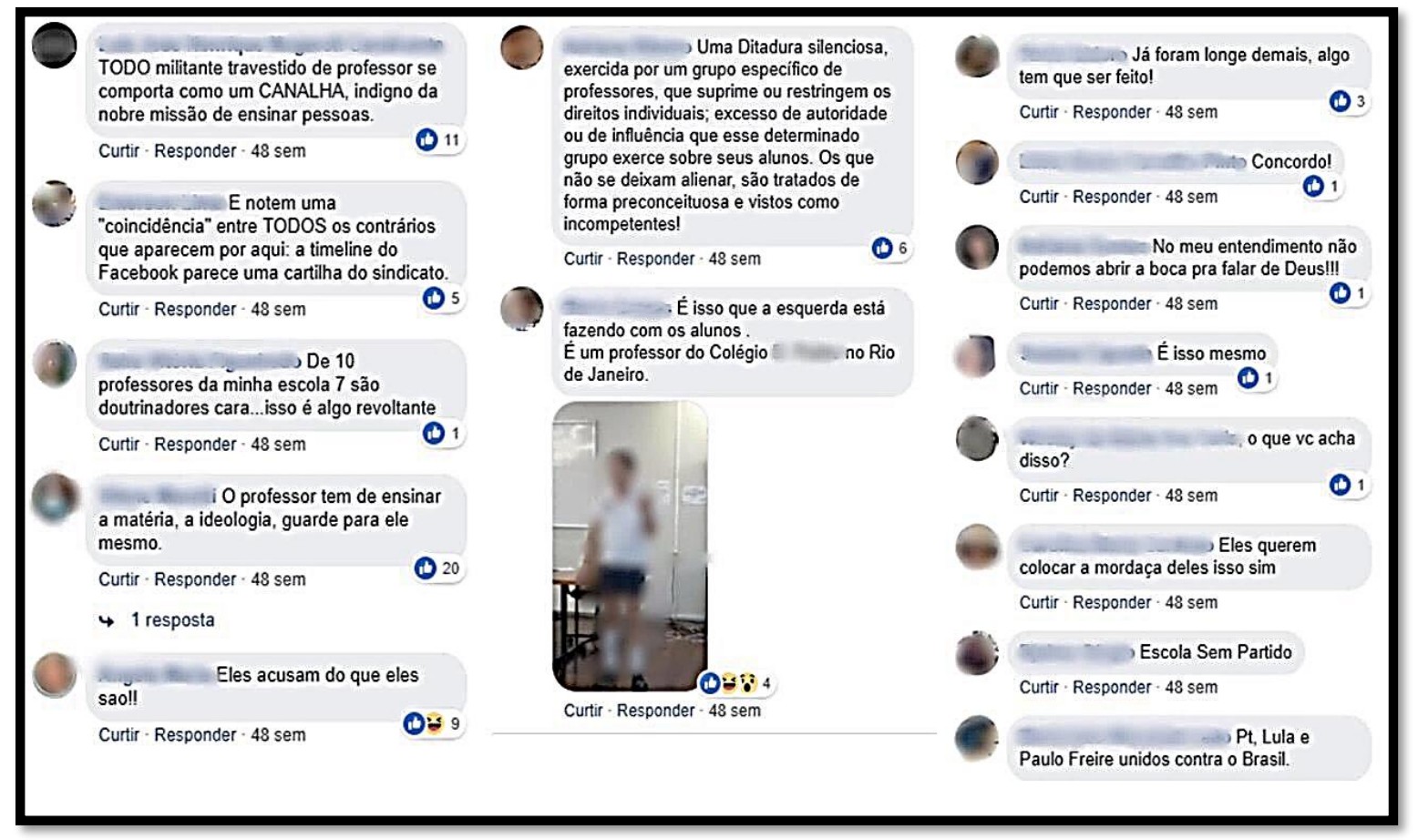

Fonte: Página oficial do Escola sem Partido - Facebook ${ }^{14}$

Essa distorção da imagem da escola e do professor é visivelmente percebida na página oficial do movimento (Anexo 2) e repetida nos comentários, por meio de termos e expressões como "militante travestido de professor", “doutrinadores”, “o professor tem

\footnotetext{
${ }^{14}$ Link de acesso:

<https://www.facebook.com/escolasempartidooficial/photos/a.346888065462191/970310926453232/? type=3\&theater . Acesso em: 7 de dez. de 2018.
} 
que ensinar matéria", "guarde a ideologia para si”, "eles querem colocar a mordaça deles isso sim!”. Essas (re)nomeações redesignam e constroem novas formas de violência e descredibilidade ao ensino, uma vez que há uma séria polarização entre ser doutrinador e ser não-doutrinador. Segundo Rajagopalan:

No momento em que é nomeado, o objeto deixa de ser exclusivo ou único, pois o próprio ato de nomeação se encarrega de emprestar-lhe um atributo (a saber, a própria descrição - definida, no caso - utilizada para nomeá-lo), que é publicamente disponível e, em princípio, apto a ser aplicado a outros objetos (RAJAGOPALAN, 2003, p. 83).

Nesse sentindo, a iterabilidade das escolhas lexicais dos simpatizantes do MESP, ressignifica, atualiza e ritualiza as práticas desta comunidade. Esses processos são percebidos ainda dentro desta publicação através de indivíduos que rechaçam “educadores doutrinadores”, criando espaços pessoais para denúncias, expondo mestres e nomes de instituições em que lecionam.

Além disso, percebe-se a busca constante em associar a invisível doutrinação com aspectos ideológicos que consideram ser de esquerda, mesclando com questões partidárias e ainda adicionando a figura de Paulo Freire ${ }^{15}$ como responsáveis pela disseminação de todo pensamento liberal/crítico. Esse aglomerado então, possibilita a criação da imagem do professor como ser inimigo da sociedade/família e põe o aluno na posição de vulnerável, retirando do Estado qualquer responsabilidade frente à crise em que se instaura no país.

Com o pretexto de acabar com a doutrinação ideológica que julgam existir no espaço escolar, testemunha-se atos de fala autoritários que limitam a liberdade de ensinar e erradica a discussão de temas transversais. Há ainda a tentativa de eliminar o caráter emancipatório do ensino, além de aniquilar espaços de diálogo, diversidade e tolerância.

Essa situação ganha ainda mais visibilidade a partir da segunda publicação, intitulada “Denuncie!". Tal postagem sucede as eleições presidenciáveis de 2018 e ganha

\footnotetext{
${ }_{15}$ Paulo Freire foi um educador, pedagogo e filósofo brasileiro. É considerado um dos pensadores mais notáveis na história da pedagogia mundial, sendo conhecido pela sua teoria de que a educação é o caminho para a emancipação e para o fortalecimento de sujeitos para que transformem sua realidade por meio da reflexão crítica. Fonte: <https://www.andes.org.br/conteudos/noticia/paulo-freire-98-anosdo-patrono-da-educacao-brasileira1> Acesso em 05 de dez. de 2019.
}

Revista Investiggações, Recife, v. 32, n. 2, p. 165 - 188, Dezembro/2019 
motivação por conta de uma deputada recentemente eleita pelo estado de Santa Catarina. Utilizando-se da visibilidade alcançada pelo cargo conquistado, a deputada abre um canal anônimo para denúncias de “docentes doutrinadores”, criando formas de legitimar práticas discursivas que colocam todos os profissionais do ensino em papel de vulnerabilidade. Mesmo havendo o pedido do Ministério Público para que tal publicação e canal fossem extintos, o pedido de denúncia ganhou capilaridade na página do MESP.

Figura 3: Publicação 2 - "Denuncie!"

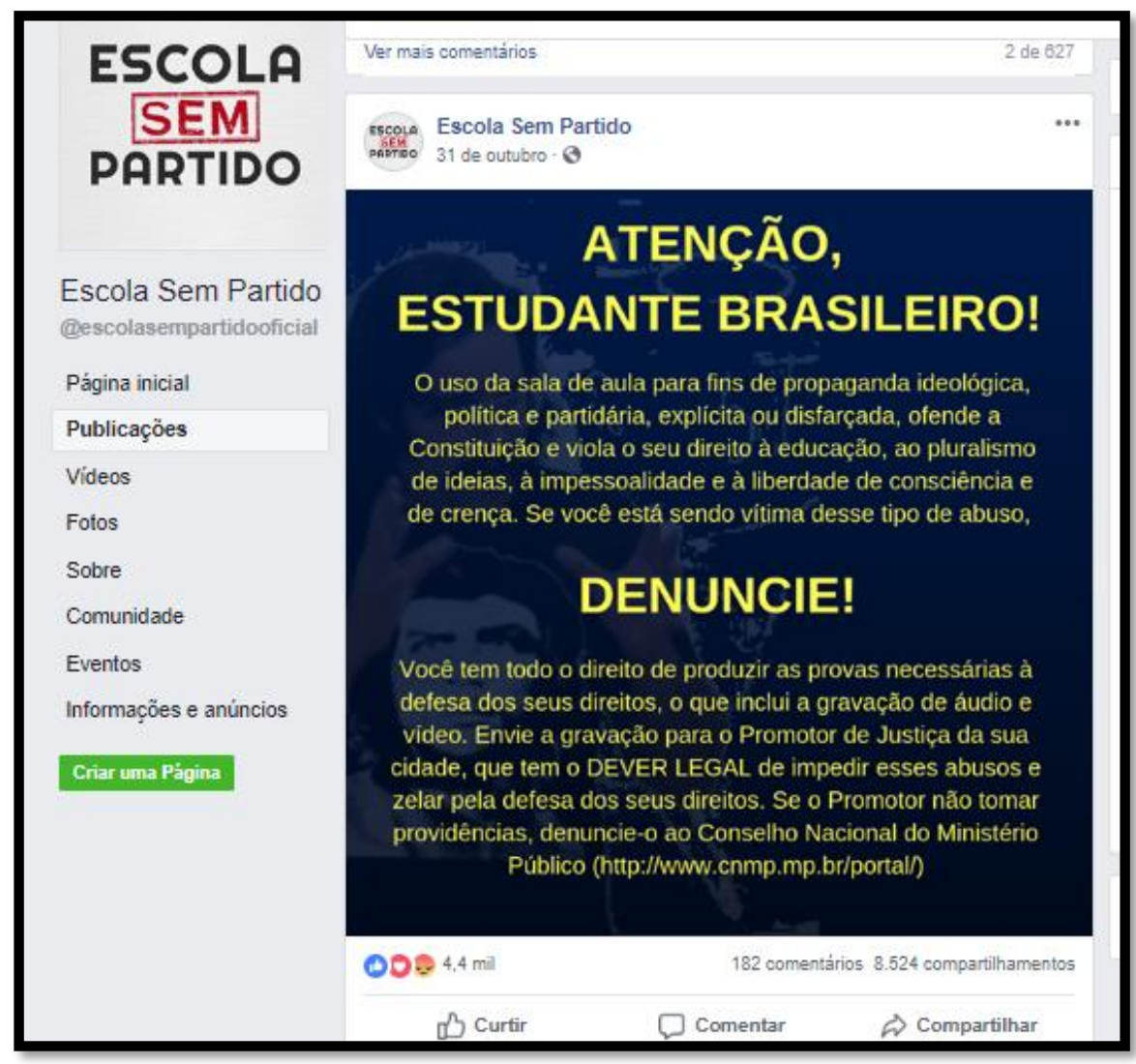

Fonte: Escola sem Partido oficial - Facebook

Na publicação "Denuncie!” há o pedido para que os estudantes que se sintam vítimas de abusos delatem seus "agressores”, através da produção de provas (vídeos ou áudios). A escolha de verbos como "ofender" e "violar" assinala a intenção comunicativa de denegrir a imagem de professores, colocando-os como seres nocivos a serem combatidos. 
Percebe-se nos comentários da publicação 2 (figura 4) que, o ritual de citacionalidade e iterabilidade possibilita a construção discursiva e efeitos performativos. Ainda munidos de discursos como "chega de doutrinação", "escola não é palanque político", "escola é para ensinar", assinala-se também para a força ilocucionária dos pedidos de denúncia incitados pela deputada, que outorgam sujeitos a operarem atos de fala violentos.

Figura 4: comentários referentes à publicação 2 - “Denuncie!”

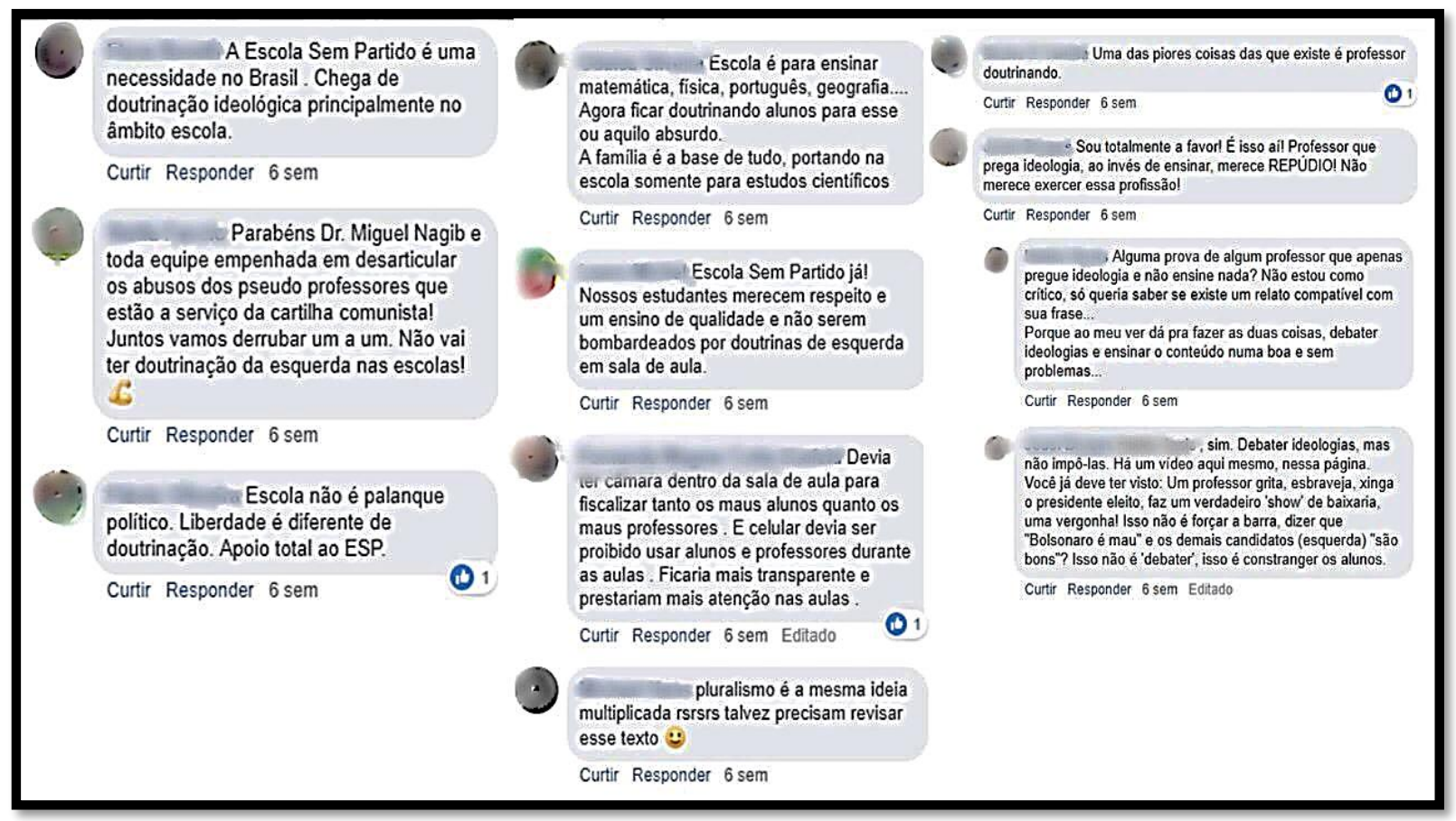

Fonte: Página oficial do Escola Sem Partido - Facebook ${ }^{16}$

O professor não é somente um doutrinador na perspectiva dos simpatizantes do MESP. O professor passa a ser objeto de uma notória degradação moral e precarização da existência por meio de comentários como "pseudo professores", "uma das piores coisas que existe é professor doutrinando", "professor que prega ideologia ao invés de ensinar merece REPÚDIO", "CANALHA, indigno da nobre missão"17.

16 Link de acesso: <https://www.facebook.com/escolasempartidooficial/posts/1176294925854830>. Acesso em: 8 de dez. de 2018.

17 Este último comentário está presente na figura 3, mas vale ser mencionado nesse quesito de degradação moral e precarização da existência por conta do seu teor comunicacional.

Revista Investigações, Recife, v. 32, n. 2, p. 165 - 188, Dezembro/2019 
Essa marginalização dos professores que não se encaixam no "padrão MESP” é fortemente sustentada e iterada através de comentários como "a família é a base de tudo", que concede à família e ao povo o falso poder hegemônico de controle da qualidade do ensino. O Ato de fala "nossos estudantes merecem respeito e ensino de qualidade e não serem bombardeados" reforça o sentido de que há uma guerra a ser vencida. A felicidade desses atos de fala também se concretiza nos comentários de reconhecimento de Nagib como sujeito que tenta "desarticular os abusos dos pseudo professores", no empenho da família brasileira em "derrubar um a um" os doutrinadores e em sugestões como "devia ter câmera dentro da sala de aula para fiscalizar tanto alunos quanto professores”.

Partindo para a análise da terceira publicação (figura 5), datada de 12 de dezembro de 2018, tem-se como notícia principal o arquivamento temporário do Projeto de Lei 7180/2014 ${ }^{18}$, ocorrido na Câmera dos Deputados Federais no dia anterior.

Figura 5: Publicação 3 - “Arquivamento do Projeto de Lei 7180/2014”

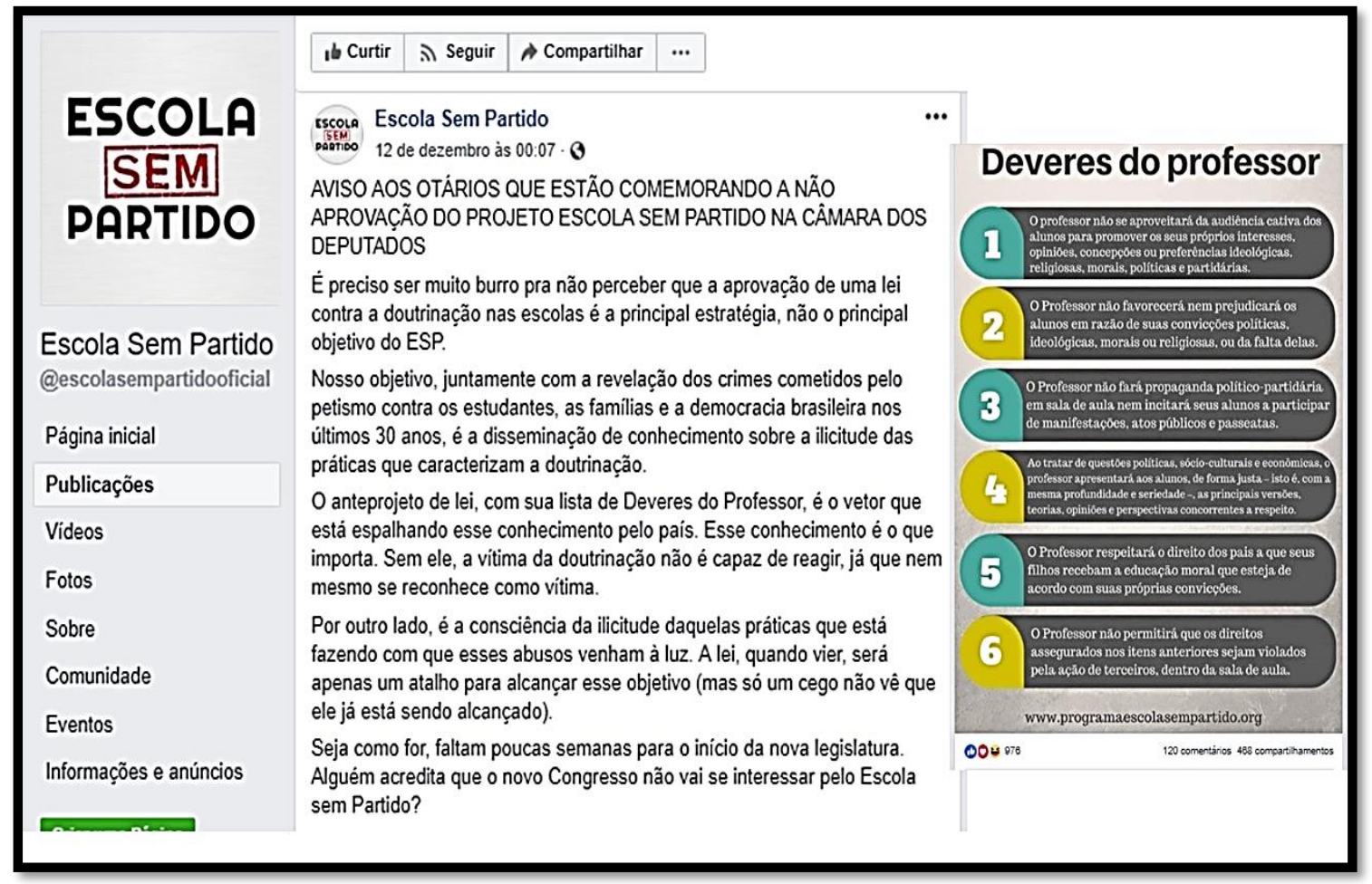

18 Disponível em:

<http://www.camara.gov.br/proposicoesWeb/prop mostrarintegra?codteor=1661955\&filename=VTS+ 1+PL718014+\%3D\%3E+PL+7180/2014>. Acesso em: 20 de dez. de 2018. 
Fonte: Escola sem Partido oficial - Facebook

Na figura 6, abaixo, repara-se na total insatisfação com o desfecho do projeto, através dos termos hostis adotados para defender a própria causa. Ainda munidos da ideia de que "a vítima da doutrinação não é capaz de reagir, já que nem mesmo se reconhece como vítima”, defendem que a principal estratégia do MESP é a revelação dos crimes e ilicitudes que rondam o agir docente. Apesar da aparente derrota, há a compreensão de que a causa ainda não está totalmente inativa, uma vez que com a chegada de um novo congresso para 2019, certamente haverá interessados em debater tais assuntos.

Figura 6: comentários referentes à publicação 3 - "arquivamento"

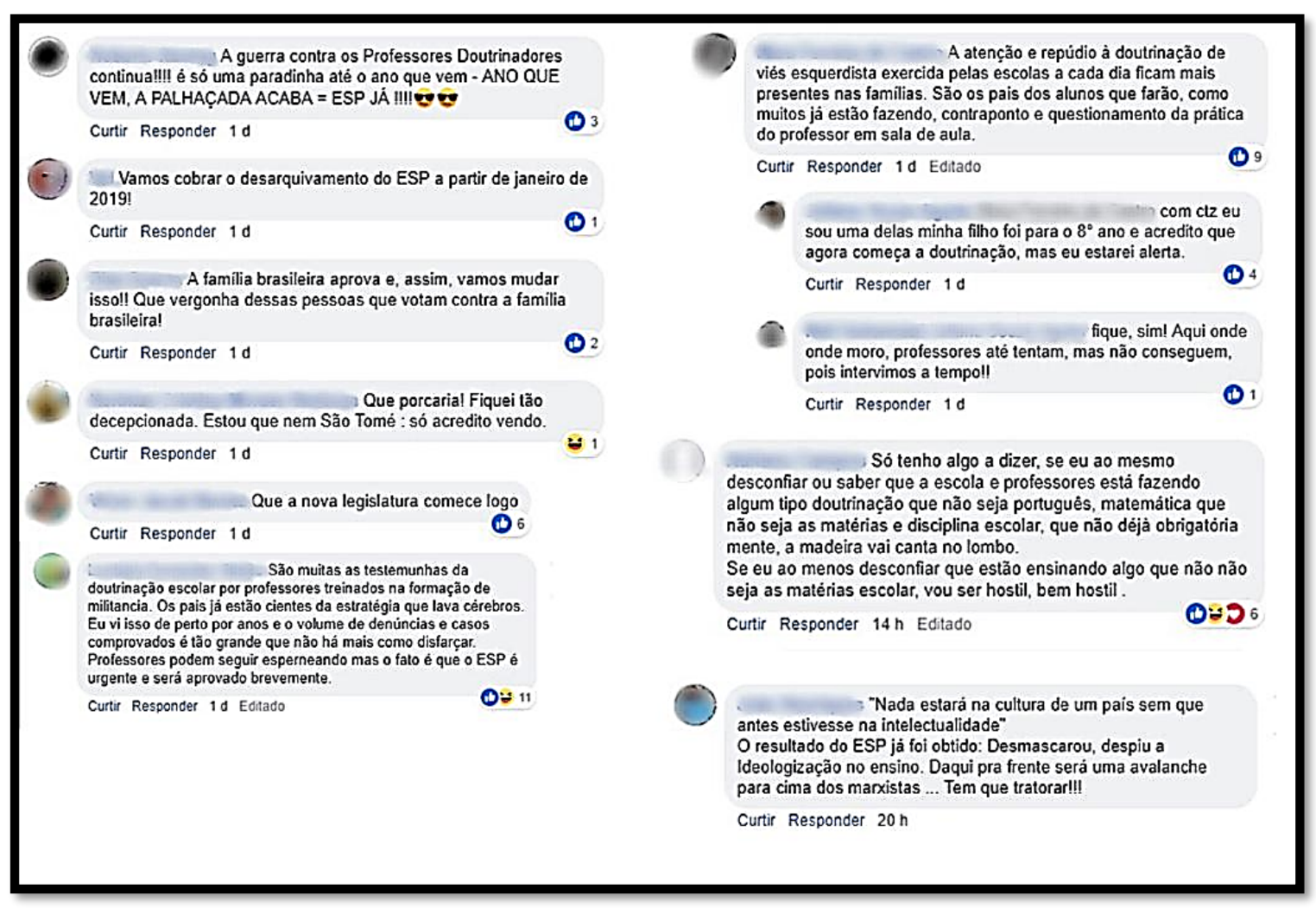

Fonte: Página oficial do Escola Sem Partido - Facebook ${ }^{19}$

19 Link de acesso:

<https://www.facebook.com/escolasempartidooficial/photos/a.346888065462191/1204955592988763/ ?type=3\&theater $>$ Acesso em: 13 de dez. de 2018.

Revista Investigações, Recife, v. 32, n. 2, p. 165 - 188, Dezembro/2019 
Nos comentários referentes ao arquivamento do Projeto de Lei 7180/2014 (figura 6), percebe-se a força ilocucionária da página oficial do MESP ao promover seu ponto de vista. Mesmo com o aparente insucesso na implementação do Escola sem Partido, atos de fala tais como "a guerra contra os professores doutrinadores continua!”, “Ano que vem a palhaçada acaba”, “A família brasileira aprova e, assim, vamos mudar isso”, "Que a nova legislatura comece logo", "vamos cobrar o desarquivamento do ESP a partir de janeiro de 2019", "professores podem seguir esperneando, mas o fato é que o ESP é urgente e será aprovado brevemente" têm por função reivindicar e impor uma série de medidas para combater professores articulados na disseminação de ideologias.

Nas palavras dos internautas, o sucesso do MESP já foi obtido, uma vez que a família brasileira já consegue identificar e desmascarar a ideologização por trás do ensino. Entretanto, atos de fala como "tem que tratorar", "a madeira vai comer no lombo" e "vou ser hostil, bem hostil" revelam a intolerância, a violência que o MESP incita, a longa inquisição docente que está por vir, sem contar os possíveis e mais desastrosos efeitos na qualidade do ensino e na diminuição pela procura por cursos de formação de professores, uma vez que a carreira não proporciona as condições mínimas de dignidade.

Desta forma, os comentários expostos nas três publicações selecionadas para se pensar o caráter performativo da linguagem nos mostram como a Teoria dos Atos de Fala proposta por Austin (1962) e também desenvolvida por Derrida (1977) e Butler (1997) é um importante constructo para se pensar o papel da linguagem em uso e suas possíveis consequências sociodiscursivas. Através dos comentários favoráveis ao conservadorismo escolar, observa-se que os atos de fala empregados pela página oficial do MESP constituem juízos de valor, pois conseguem promover intervenções na opinião da população brasileira. Consequentemente, a linguagem dos comentários é fortemente performativa, à medida que incita, realiza e naturaliza visões repulsivas contra a escola e o professor.

\section{Conclusão}

Em face das inquietações político-educacionais em torno do agir docente, surge o objetivo geral desta pesquisa, o qual consistiu em explorar o caráter performativo da 
linguagem do Movimento Escola sem Partido. Inicialmente proposto por Miguel Nagib em 2004, o movimento vem ganhando adeptos a partir dos projetos de leis e de suas fortes ações em redes sociais, por meio de compartilhamento de publicações, vídeos e depoimentos de indivíduos que reivindicam a imparcialidade do professor em sala de aula. Tendo como base a Teoria dos Atos de Fala de Austin (1962), buscou-se explorar como se dá a emergência, a circulação, a ritualização e a legitimação desses discursos que marginalizam os professores, desqualificam o ensino brasileiro, silenciam vozes e apagam as diversidades.

A fim de encaminhar tal pesquisa foram analisados os comentários online de três publicações existentes na página oficial do MESP e disponibilizadas na rede social Facebook. Levando em consideração os princípios austinianos de que dizer é fazer, foi possível verificar que os discursos performados pelos simpatizantes do MESP encenam um violento processo de subjugação. Utilizando-se de termos hostis como "canalha", “indigno da nobre missão", "pseudo professores”, “doutrinadores”, “repúdio à doutrinação", as forças conservadoras encontram nas redes sociais um campo de comunicabilidade onde é possível construir a imagem de um professor como uma grande ameaça à nação. Os usuários destes meios de comunicação são interpelados a compartilhar desse olhar marginalizado, de modo a ser preciso escolher um lado do embate. A suposta "defesa da família e da nação" leva à perseguição de professores por meio de denúncias e exposição da figura docente.

O forte caráter apelativo da linguagem empregada pelo MESP é capaz de renomear, redesignar e subverter o papel social do professor e de mobilizar uma série de debates sobre o modo como a educação brasileira é e deve ser conduzida. Essas ações ganham ainda mais força através nas redes sociais porque o aspecto de responsabilidade pelas palavras proferidas e atos cometidos parecem ser questões ausentes de assinatura. Nesse sentido, os atos de fala performados contra os professores geram atos de dominação e coerção, legitimando uma estrutura social representada por relações políticas conservadoras do status quo.

Finalmente, se as ideias defendidas por Mey (2001) de que a linguagem nasce da necessidade de os indivíduos em nomear e transformar o mundo que os rodeia e de que a coletividade detém o poder da criação e do controle dos meios comunicativos, logo, a Teoria dos atos de fala de Austin (1962) é um importante constructo para se pensar a Revista Investigações, Recife, v. 32, n. 2, p. 165 - 180, Dezembro/2019 
importância da linguagem em uso, bem como as sérias implicações éticas, sociais, políticas por trás desses discursos situados. Compreende-se aqui que a linguagem já não pode ser tratada mediante uma postura descritiva. A Teoria dos atos de fala vai ao encontro de uma Linguística que se propõe a "refletir criticamente sobre as causas subjacentes dos fenômenos por ela estudados e a natureza da sociedade que usa certa(s) língua(s)” (FOWLER \& KRESS, 1979, p. 186). Desta forma, elucidar os discursos conservadores do MESP por meio da Teoria dos atos de fala é uma maneira de colocarmos em discussão questões pertinentes sobre a violência linguística, uma vez que tais atos possuem um caráter perlocucionário, capazes de acionar o ódio, a intolerância, a perseguição e o apagamento de visões críticas e plurais.

\section{Referências}

AUSTIN, John Langshaw. How to do things with words. Oxford: Oxford University Press, 1962.

BOYD, Danah. Social Network Sites as Networked Publics: Affordances, Dynamics, and Implications. In: PAPACHARISSI, Zizi (ed.). Networked Self: Identity, Community, and Culture on Social Network Sites. Routledge, p. 39-58, 2010.

BRASIL. Lei de Diretrizes e Bases da Educação Nacional. Lei número 9394, 20 de dezembro de 1996. Disponível em:

<http://www.planalto.gov.br/ccivil 03/LEIS/L9394.htm>. Acesso em: 20 de dez. de $\underline{2018 .}$

. Projeto de lei 718o/2014. Brasília: Câmara dos Deputados, 2014. Disponível em: <https://www.camara.leg.br/proposicoesWeb/prop mostrarintegra?codteor=1661955\&f ilename $=\mathrm{VTS}+1+\mathrm{PL} 718014+\% 3 \mathrm{D} \% 3 \mathrm{E}+\mathrm{PL}+7180 / 2014>$. Acesso em: 20 de dez. de 2018.

BUTLER, Judith. Excitable speech: a politics of the performative. New York: Routledge, 1997.

DERRIDA, Jacques. Assinatura acontecimento contexto. In: Derrida, J. Limited Inc. Campinas: Papirus, 1977. 
ESCOLA SEM PARTIDO. Educação sem doutrinação. Conteúdo disponibilizado em todo o site. Disponível em: <http://escolasempartido.org/>. Acesso em: 19 de nov. de 2018.

FOWLER, Roger; KRESS, Gunther. Critical Linguistics. In: Fowler, R., Hodge, B., Kress, G., Trew, T., Language and control. London: Routledge \& Kegan Paul, pp. 185-213, 1979. MEY, Jacob L. Pragmatics: An Introduction. London: Blackwell, 2001.

NUNAN, David. Case Study. In: Research methods in language learning. Cambridge: Cambridge University, 1992.

RAJAGOPALAN, Kanavillil. Por uma linguística crítica. Linguagem, identidade e a questão ética. São Paulo: Parábola Editorial, 2003.

RAJAGOPALAN, Kanavillil. Nova pragmática: fases e feições de um fazer. São Paulo: Parábola Editorial, 2010.

RECUERO, Raquel; SOARES, Priscilla. Violência simbólica e redes sociais no facebook: o caso da fanpage "Diva Depressão". Galáxia (São Paulo), vol.13, n.26, pp. 239-254, 2013. RIO DE JANEIRO. Assembleia Legislativa. Projeto de Lei n. 2974/2014. Cria, no âmbito do sistema de ensino do Estado do Rio de Janeiro, o "Programa Escola sem Partido". Disponível em:

<http://alerjln1.alerj.rj.gov.br/scpro1115.nsf/e4bb858a5b3d42e383256ceeoo6ab66a/45741 a7ezccdc50a83257c980062a2c2?OpenDocument>. Acesso em: 20 de dez. de 2018.

\section{Anexo}

Anexo 1: Cartaz com os deveres do professor 


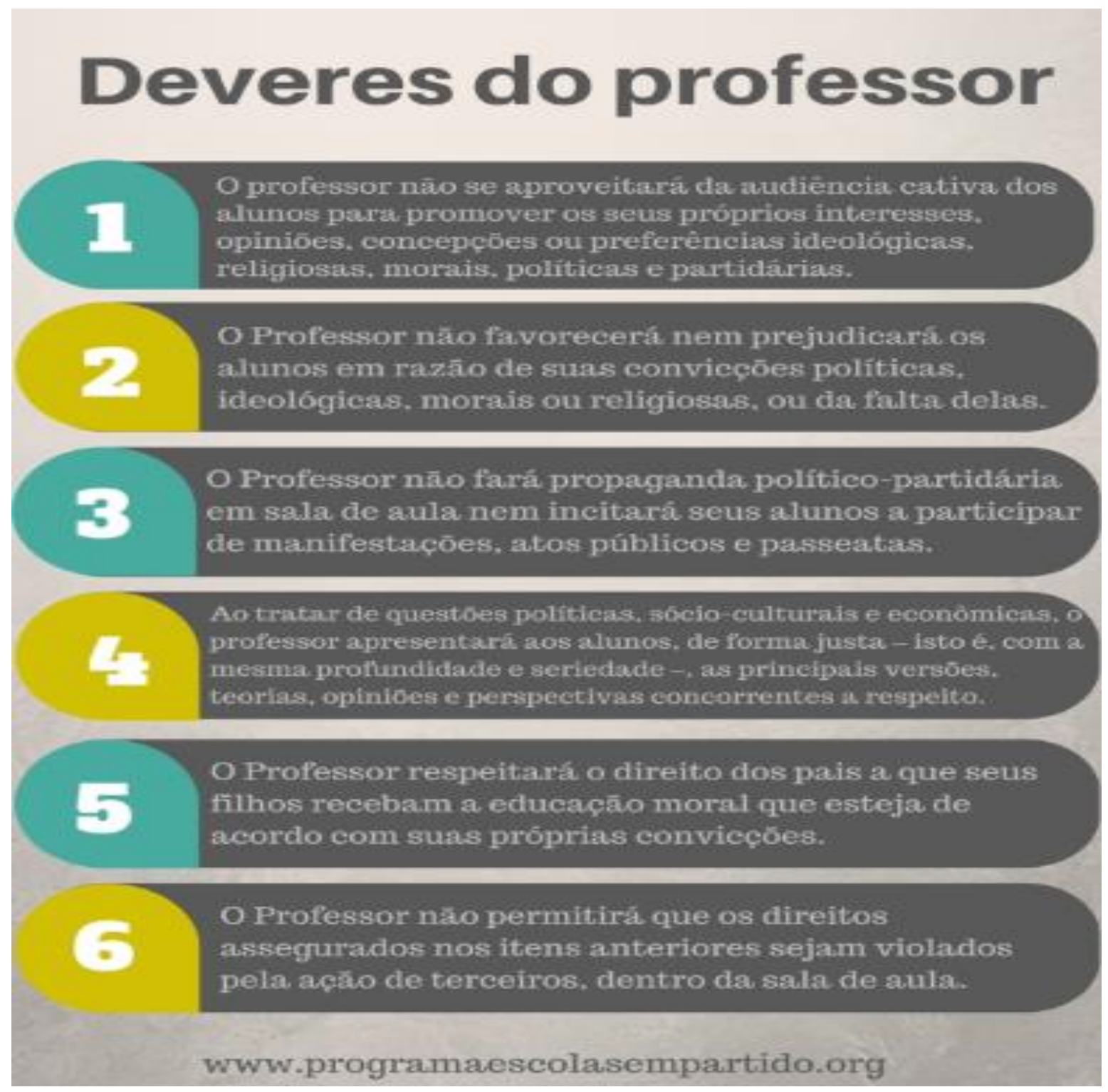

Fonte: <https://www.programaescolasempartido.org/>

Anexo 2: Página oficial do movimento escola sem partido 


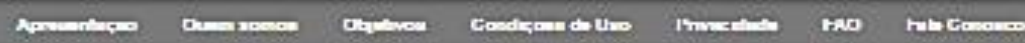

- HOME

- hrtigos

- corpo de deutto

- defenon seu fluo

- depcinentog

- doutrina da

DOUTRINaCAOO

- doutrinacao felo

MUNDO

- educactá MCRrl

- o fapel do gonerno

- livros didaticos

- midia

- MONmento

ESTUDANTIL

- representacoes ano

MP

- sindromede

ESTCCOLMO

- universidades

- vestibular

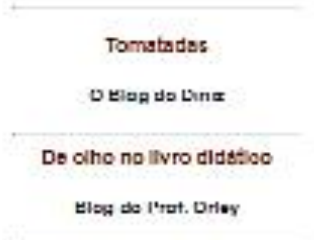

Nao dalxo que ceu prefecser fapso Ieso oom voot.

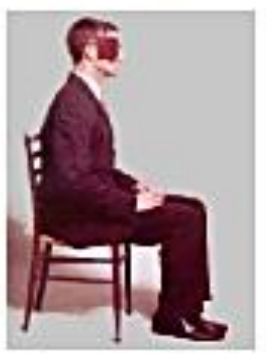

Denuncie!

Enfin, o tama musisal da odusogata bracilibira

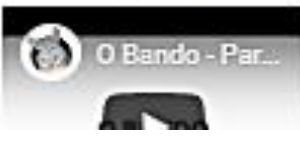

\section{MP processa colégio particular} de $\mathrm{BH}$ por martelar ideologia de gênero na cabeça dos alunos

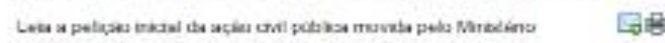

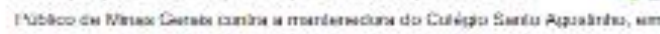

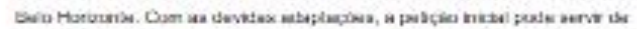

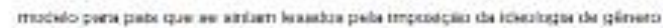

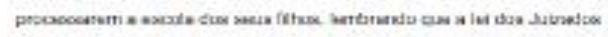

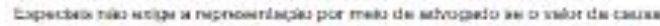
fur mbenar a 211 setiencox minaras.

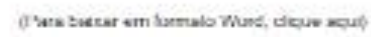

Lets max.

\section{Leia o parecer do relator do} Projeto Escola sem Partido na Câmara dos Deputados

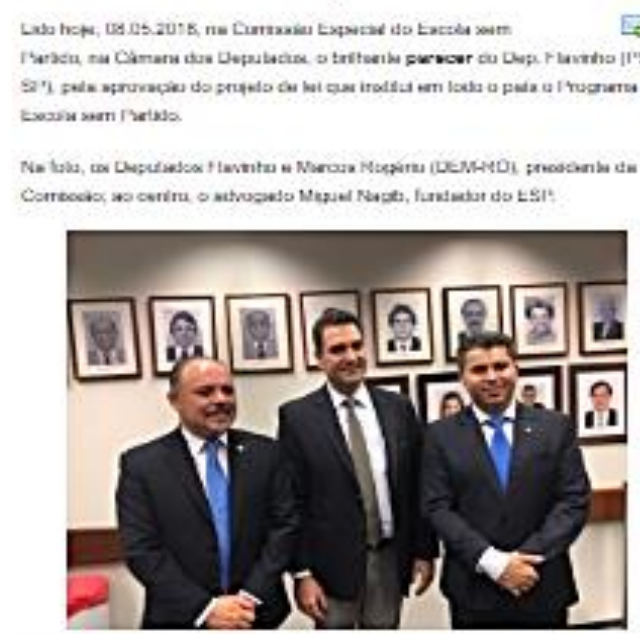

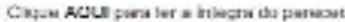

\section{Flagrante de doutrinação em escola de Santa Catarina.}

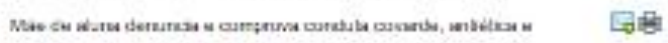

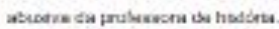

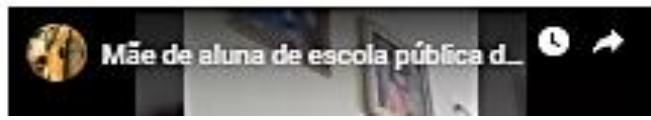

\begin{tabular}{l|l|}
\hline Faguisar & Dr \\
\hline
\end{tabular}

POR UMA LEI CONTRA

O ABU SO DA

LIBERDADE DE ENSINAR

MODELO DE

NOTIFICACC.ZO

EXTRAJUDICIAL

CARTAZ COM OS

DEVERES DO

PROFESSOR

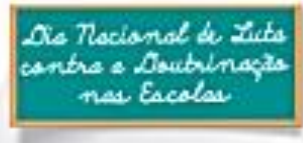

Deseres da

Prefescar

Btapranda a Doubinader

Peruje sue

Denuarcia

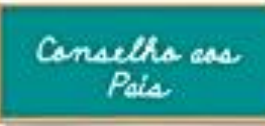

\section{$\cos \operatorname{coc}$}

NAO DEXE DELER:

- Professear niso tem alvetio de Tazer a cabsop" de aluno.

- Qusm alsese que aducsoso sexual 4 contedodo abrigatsirio?

Fonte: <https://www.programaescolasempartido.org>

* Doutoranda em Linguística pela Universidade Federal de Santa Catarina (UFSC). 